\title{
A TEORIA HOLÍSTICO-CONFIGURACIONAL DE PESSOA NA FILOSOFIA ESTRUTURAL-SISTEMÁTICA *
}

The Holistic-Configurational Theory of Person in the Structural-Systematic Philosophy

Wellistony C. Viana **

Resumo: $\mathrm{O}$ debate sobre a metafísica da pessoa adquiriu destaque na filosofia analítica nas últimas décadas. Isso é explicado por vários fatores, entre eles o antigo e sempre novo interesse em querer obter a resposta para a pergunta: quem sou eu? No cenário atual, o debate acerca do status ontológico da pessoa tem sido realizado por vários tipos de teorias, desde dualistas até as diversas versões do fisicalismo. $O$ grande problema do debate constitui a pressuposição de uma ontologia geral e semântica não explicitadas ou incoerentes. No presente artigo, apresentamos a teoria holístico-configuracional de pessoa (THC) da Filosofia Estrutural-Sistemática (FES). A característica básica desta posição consiste na abordagem da pessoa num quadro teórico mais abrangente, no qual mente e corpo são vistos como dimensões interconectadas de um todo. De fato, estados mentais e físicos pertencem à dimensão oniabrangente do Ser como tal e em seu todo, o que revela uma nova perspectiva capaz de dissolver o impasse clássico da interação mente-cérebro.

Palavras-chave: Metafísica. Pessoa. Fisicalismo. Filosofia Estrutural-Sistemática. Visão constitucional.

Abstract: The debate on the metaphysics of person has gained prominence in analytical philosophy in recent decades. This is explained by several factors,

* Artigo recebido em 01/07/2020 e aprovado para publicação em 15/09/2020.

** Doutor em Filosofia pela Hochschule für Philosophie de Munique-Alemanha. Atua nas áreas de metafísica e filosofia da mente. Atualmente trabalha como professor na Pontificia Università Gregoriana-Roma. 
among them the perpetual interest in finding an answer to 'who am I?' In the current scenario, the debate on the ontological status of the person has been carried out by various types of theories, from dualist approaches to different versions of physicalism. The central problem of the debate is the assumption of a general ontology and a semantics that are not explicit or incoherent. In this paper, we present the holistic configurational theory of personhood (HCT) of the Structural-Systematic Philosophy (SSP). The essential feature of this position is the approach to understanding the person in a more comprehensive theoretical framework, in which mind and body are seen as interconnected dimensions of the whole. Indeed, the mental and physical states belong to the all-embracing dimension of Being as such and as a whole, which reveals a new perspective capable of dissolving the classic impasse of mind-brain interaction.

Keywords: Metaphysics. Person. Physicalism. Structural-systematic. Philosophy. Constitutional view.

\section{A} visão tradicional de "pessoa" se encontra em Boécio em seu "De persona et duabus naturis", cap. III: "persona est naturæ rationalis individua substantia" ("pessoa é um indivíduo substancial de natureza racional"). Esta concepção clássica sofreu muitas críticas ao longo da história e, mais ainda, no atual contexto. Praticamente todos os termos dessa definição se envolvem em grandes polêmicas: o que é um indivíduo e qual a condição suficiente para uma individuação? Possui a pessoa humana uma "natureza" ou é ela puramente histórica e cultural? Qual a relação entre racionalidade e conexões neuronais, há uma dependência intrínseca da racionalidade em relação ao cérebro? Por fim, constitui a ontologia da substância uma teoria coerente?

A concepção clássica revista pelos modernos, sobretudo por Descartes, trouxe ainda maiores dificuldades. Descartes divide a pessoa em duas substâncias completas, independentes e separáveis, inaugurando um dualismo que teve consequências nefastas para a filosofia e ciência. A objeção básica à teoria cartesiana foi bem formulada pela jovem princesa Elisabete da Boêmia em 1643, quando perguntou numa carta dirigida a Descartes como seria possível uma interação entre estas duas substâncias, uma vez que res extensa e res cogitans representavam duas entidades incompatíveis em suas propriedades. A questão influenciou grande parte dos filósofos pós cartesianos, que procuraram resolver o imbróglio, negando a originalidade ontológica seja da res extensa (e.g., os vários tipos de idealismos), seja da res cogitans (e.g., os vários tipos de materialismo). De um lado, dualistas procuraram salvaguardar a diferença ontológica entre corpo e espírito, mas sem saber como dar conta da interação entre eles. De outro lado, monistas quiseram resolver o problema da interação reduzindo uma dimensão à outra, mas caindo no problema de não conseguir render conta da novidade ontológica de uma das dimensões. Enquanto posições dua- 
listas ficaram fora de moda, as monistas encontraram novas formas de se apresentar, sobretudo tentando incorporar traços dualistas "aceitáveis". É nesse sentido que surgiram as teorias fisicalistas não-reducionistas, que praticamente dominam hoje o debate acerca da pessoa. Entre elas se encontram a visão psicológica, a visão biológica e a visão constitucional.

A Filosofia Estrutural-Sistemática (FES) ${ }^{1}$ também rejeita a concepção de Boécio em sua formulação ontológica, da mesma forma que rejeita o dualismo radical de Descartes. Embora ambas as concepções tenham um aspecto positivo, a saber: defendem a especificidade ontológica do corpo e da alma, elas não souberam organizar estas características num todo coerente. No presente artigo, apresentamos uma teoria holístico-configuracional de pessoa (THC), que pretende conciliar a originalidade ontológica de estados mentais com sua capacidade de interagir com o mundo físico. Embora tenha intenções parecidas com as do fisicalismo não reducionista, a THC não apresenta a incoerência fundamental daquela concepção. A ideia básica da nova proposta é dissolver o enigma da interação com a tematização de uma dimensão oniabrangente, capaz de abarcar o mental e o físico, a saber: a dimensão compreensiva do Ser.

Procedemos aqui da seguinte forma: primeiro, apresentamos brevemente uma das posições fisicalistas não reducionistas mais promissoras da atualidade, a saber: a visão constitucional de pessoa de Lynne R. Baker (1). Em seguida, levantamos algumas críticas a esta posição, sobretudo a incoerência de sua ontologia geral e ontologia da substância (2). Depois, apresentamos o quadro teórico da FES (3) e sua (sub)teoria holístico-configuracional de pessoa (4). Por fim, mostramos como a teoria lida com algumas dificuldades clássicas da metafísica da pessoa (5).

\section{A Visão Constitucional de Lynne R. Baker}

Lynne Rudder Baker tem desenvolvido uma concepção de pessoa contraposta às clássicas posições lockeana da memória e biológica ou animalista. Enquanto as primeiras identificam a pessoa com suas memórias, as segundas a identificam com seu corpo. Baker critica as duas posições, embora sua visão esteja mais ligada à corrente lockeana. Para Baker, a pessoa é caracterizada por uma perspectiva em primeira pessoa constituída por um corpo, dando o nome de Visão Constitucional de Pessoa (VCP) ao seu

\footnotetext{
${ }^{1}$ A Filosofia Estrutural-Sistemática encontra seus fundamentos no livro de L. B. Puntel Struktur und Sein (2006). Citamos ao longo do texto a tradução em português: PUNTEL, L.B., Estrutura e ser. Um quadro referencial teórico para uma filosofia sistemática. Trad. Nélio Schneider, São Leopoldo, Ed. Unisinos, 2008.
} 
programa. Para a $\mathrm{VCP}$, pessoas não são idênticas ao seu corpo ou às suas memórias, mas constituem uma entidade ontológica original. Para defender esta tese, Baker afirma uma diferença fundamental entre constituição e identidade, pelo menos no modo como "identidade" vem entendida na mereologia. A pessoa seria constituída pelo corpo, mas não estritamente idêntica a ele. Ou seja: enquanto o conceito de "identidade" (geralmente) implica o modo da necessidade, o conceito de "constituição" se refere ao modo da contingência. De fato, "constituição" para Baker seria um tipo de "identidade contingente", representado da seguinte forma:

$$
\mathrm{IC}_{\text {def }}: \mathrm{x}=\mathrm{y} \rightarrow \nabla(\mathrm{x}=\mathrm{y})
$$

A ideia de constituição retoma a concepção aristotélica de matéria e forma, que Aristóteles explicita com o exemplo da estátua de Apolo. A estátua não é idêntica ao mármore no sentido de haver uma identidade necessária entre a estátua de Apolo e o mármore. É preciso distinguir, segundo Baker, propriedades essenciais e propriedades não essenciais na relação de constituição. As primeiras, consistem naquilo que faz com que o mármore seja mármore e a estátua de Apolo seja uma estátua de Apolo, enquanto as segundas são aquelas partilhadas pela estátua de Apolo e pelo mármore devido à relação constitucional. Ou seja, a propriedade que faz com que a estátua de Apolo seja uma estátua de Apolo não é a propriedade "ser mármore", uma vez que se poderia ter uma estátua de Apolo também de barro ou bronze. Porém, porque a estátua de Apolo é constituída pelo mármore, ambas compartilham propriedades não-essenciais, como por exemplo, "pesar 10kg". Baker chama propriedades essenciais de "não-derivadas" (nonderivative property) e propriedades não essenciais de "derivadas" (derivative property). A propriedade não-derivada diz o que uma coisa é fundamentalmente e a propriedade derivada é possuída por algo que tem uma propriedade não-derivada devido à relação de "constituição". Se $x$ é constituído por $y$ em $\mathrm{t}$, significa que $x$ possui uma propriedade não derivada que o define como $x$, por exemplo, $\mathrm{P} 1 \mathrm{e}$, ao mesmo tempo, possui uma propriedade derivada y pela qual é constituída, por exemplo, P2. Nesse caso, $x$ é estritamente idêntico a P1, mas contingentemente idêntico a $y$, que tem $\mathrm{P} 2$ como propriedade essencial, isto é, $x$ e $y$ compartilham as propriedades $\mathrm{P} 1$ e P2 em t, mas de maneira diferente. Por fim, a ideia de constituição daria à $x$ e $y$ uma unidade genuína.

Aplicada à pessoa, a distinção entre propriedades não-derivadas e derivadas traz o seguinte resultado: a pessoa não é idêntica ao seu corpo porque não possui a corporalidade como propriedade não-derivada, mas apenas como propriedade derivada por causa da relação constitucional. O

\footnotetext{
${ }^{2} \mathrm{O}$ símbolo $\nabla$ é utilizado aqui para a modalidade da contingência. Esse símbolo foi introduzido por Montgomery e Routley, cf. MONTGOMERY, H. A./ROUTLEY, F. R., Contingency and non-contingency bases for normal modal logics. LA Vol. 9 (no. 35-36), 1966, p. 318-328.
} 
que faz com que uma pessoa seja pessoa não é seu corpo, mas, segundo Baker, uma perspectiva em primeira pessoa (PPP). A pessoa é constituída por um corpo, o que significa: 1) a pessoa é idêntica à sua PPP e 2) a pessoa compartilha algumas propriedades com o corpo. Se o corpo de Paulo pesa $70 \mathrm{~kg}$, então é Paulo quem pesa $70 \mathrm{~kg}$, mas apenas de forma derivada e não enquanto é pessoa. Se Paulo tem atos intencionais, então seu corpo também compartilha de forma derivada de tal propriedade. Para Baker, afirmar que Paulo é (não-derivadamente) sua PPP $e$ Paulo é (derivadamente) seu corpo, não significa que existem dois Paulos em um mesmo lugar (too many minds problem), mas apenas que Paulo é constituído por um corpo.

A PPP consiste na capacidade de ter uma vida interior e tomar decisões livres a partir de crenças e desejos, em uma palavra, consiste na autoconsciência que seres humanos apresentam. Segundo Baker, a PPP não é um fator apenas psicológico e reduzível a estados neuronais, mas possui um status ontológico específico, fazendo diferença causal no mundo físico. Para muitos críticos, este é um sinal de que a VCP defende uma espécie de dualismo e imaterialismo. No entanto, Baker professa claramente um fisicalismo não-reducionista, no qual vem afirmado um monismo fisicalista junto a um dualismo de propriedades. De um lado, propriedades mentais, como a PPP, fazem ontologicamente parte do mundo material; de outro lado, elas são causalmente eficazes e não podem ser reduzidas a propriedades físicas ${ }^{3}$.

\section{Problemas da Visão Constitucional de Pessoa}

O grande mérito da VCP é aquele de procurar resgatar a especificidade ontológica de estados mentais sem tentar reduzi-los a estados físicos. Para Baker, a ideia de "constituição" representa o conceito chave, através do qual é possível distinguir propriedades não-derivadas de propriedades derivadas, unindo-as numa unidade primária. No entanto, a busca de conciliação entre dualismo e fisicalismo leva a VCP à uma incoerência radical. Nesse ponto, levantamos pelo menos três críticas que se podem fazer à $\mathrm{VCP}$, a fim de evidenciar melhor como a teoria holístico-configuracional da FES resolve tais dificuldades.

[1] O primeiro problema da VCP constitui sua ontologia geral. A este respeito duas incoerências podem ser mostradas: 1) a incoerência de seu fisicalismo não-reducionista e 2) a incoerência da ontologia da substância

${ }^{3}$ Cf. BAKER, L.R., "Nonreductive Materialism". In: MCLAUGHLIN, B./BECKERMANN, A. (eds.), The Oxford Handbook for the Philosophy of Mind. Oxford: Oxford University Press. 2008, p. 109-120. 
assumida. A primeira incoerência advém do fato de que o fisicalismo não reducionista sinaliza para a novidade dos estados mentais em relação aos estados físicos através de uma suposta irredutibilidade, que não vem definida com precisão, ou seja: persiste uma incoerência insuperável ao se afirmar um monismo físico para todas as entidades, ao mesmo tempo em que uma "diferença" entre níveis ontológicos vem defendida. A segunda incoerência advém da assunção da ontologia da substância, pois, embora rejeitando o dualismo cartesiano de substâncias e aceitando apenas substâncias materiais com dualismo de propriedades, a VCP não reflete sobre a coerência dessa ontologia e semântica. Vejamos de perto cada uma dessas incoerências.

O fisicalismo não reducionista surge como uma forma de resolver o problema da interação psicofísica, criada por Descartes, a saber: ao tempo em que procura salvar a peculiaridade ontológica de estados mentais (através da sua irredutibilidade), também afirma a eficácia causal do mental no mundo físico (contra o epifenomenalismo). Em geral, o fisicalismo não-reducionista defende três teses: 1a) propriedades mentais são diferentes de propriedades físicas; 2 a) existe uma dependência de propriedades mentais sobre propriedades físicas e 3a) propriedades mentais são causalmente eficazes ${ }^{4}$. A dificuldade é que as três teses são difíceis de conciliar, sobretudo, as teses 1a) e 2a), dependendo do grau de "superveniência" entre estados mentais e físicos, que pode ser muito fraco ou brando (possibilitando a "diferença" atestada na tese 1a), ou ainda forte ou muito forte (impossibilitando a "diferença" afirmada na tese $1 \mathrm{a})^{5}$.

Baker chama sua versão fisicalista não-reducionista de "PC-View" (visão de propriedades constitucionais), na qual ela pretende defender três concepções: 1b) propriedades podem ter diferentes níveis ontológicos (dando razão à tese $1 \mathrm{a}) ; 2 \mathrm{~b}$ ) constituição de propriedades (supostamente apoiando tese $2 a$ ) e $3 b$ ) independência da eficácia causal (sustentando tese 3a). Em sua visão, a concepção de diferentes níveis ontológicos deve ser conciliada com a tese da dependência entre tais níveis a partir da relação de constituição. Sua ideia é a seguinte: na relação de constituição, encontramos propriedades em diferentes níveis ontológicos com poderes causais diferentes, ao mesmo tempo em que há uma dependência entre estes níveis. Por exemplo, devido à relação constitucional, uma estátua

\footnotetext{
${ }^{4}$ Cf. BAKER, L.R., "Nonreductive Materialism". In: MCLAUGHLIN, B./BECKERMANN, A. (eds.), The Oxford Handbook for the Philosophy of Mind. Oxford: Oxford University Press. 2008, p. 110s.

${ }^{5}$ A relação de superveniência possui três características: 1) covariância; 2) determinação e 3) irredutibilidade. No entanto, vale ressaltar que as características 1) e 3) são inversamente proporcionais, ou seja: quanto maior for a covariância, menor será a irredutibilidade e vice-versa. Uma covariância 0 entre mental e físico, eleva ao máximo a irredutibilidade, gerando o dualismo; por outro lado, uma covariância máxima levaria à total redução do mental ao físico, gerando o fisicalismo. Cf. VIANA, W.C., Hans Jonas e a filosofia da mente, São Paulo: Paulus, 2016, p. 70-72.
} 
que possui uma propriedade não-derivada de "ser um artefato estético" tem não apenas um poder causal em seu nível ontológico (e.g., o poder de seduzir um comprador), mas também compartilha o poder causal de propriedades num nível inferior (e.g., o poder de esmagar uma barata). Por outro lado, há uma dependência da propriedade "ser um artefato estético" da propriedade "ser de bronze", uma vez que a estátua é constituída pelo bronze. Porque tais propriedades têm poderes causais diferentes, Baker pensa justificar a tese $1 \mathrm{~b}$ ) de seu fisicalismo não-reducionista. Para justificar a tese $2 b$ ) (da dependência ontológica), ela afirma que há dois tipos de dependência, uma necessária e estrita (superveniência), outra ampla e contingente (constitucional). E neste ponto, encontramos o problema. Cito aqui todo um parágrafo de Baker:

Em que, então, reside a dependência do mental do físico, ou mais geralmente, das instâncias de propriedade constituídas de seus constituintes? Apesar de constituição não ser em si uma relação de superveniência, onde existe constituição, existe uma relação de superveniência por perto. Uma instância de propriedade constituída supervem, em última análise, em seus constituintes subatômicos, juntamente com a superveniência microfísica base de todas as circunstâncias em que a instância da relação de constituição é obtida. A base de superveniência será muito ampla - ampla demais para ser especificada ou útil para explicação - mas será metafisicamente suficiente para a instância de propriedade constituída ${ }^{6}$.

Baker afirma que onde há constituição, há também superveniência: "Apesar de constituição não ser em si uma relação de superveniência, onde existe constituição, existe uma relação de superveniência por perto". Ou seja, de uma parte, como um "vero" fisicalista, Baker afirma que todas as entidades supervêm, no fim das contas, sobre entidades físicas: "uma instância de propriedade constituída supervem, em última análise, em seus constituintes subatômicos, juntamente com a superveniência microfísica base de todas as circunstâncias em que a instância da relação de constituição é obtida". Ora, para ser realmente um fisicalista, tal superveniência precisa ser forte ao ponto da identidade, em que entidades superiores são (no sentido de identidade) ou podem ser reduzidas a entidades físicas. Uma superveniência fraca traria um problema para o fisicalista, a saber: persistiria um resíduo de "independência" ou "irredutibilidade" que arruinaria sua posição,

\footnotetext{
6 "Wherein, then, lies the dependence of the mental on the physical, or more generally, of the constituted property instances on their constituters? Although constitution is not itself a supervenience relation, where there is constitution, there is a supervenience relation in the neighborhood. A constituted property-instance supervenes ultimately on its subatomic constituters together with the microphysical supervenience base of all the circumstances in which the instance of the constitution relation obtains. The supervenience base will be very broad - too broad to be specified or to be useful in explanation - but it will be metaphysically sufficient for the constituted property instance" (BAKER, L. R., "Nonreductive Materialism". In: MCLAUGHLIN, B./BECKERMANN, A. (eds.), The Oxford Handbook for the Philosophy of Mind. Oxford: Oxford University Press, 2009, p. 123)
} 
caso não encontrasse um meio de reduzir ou eliminar tal resíduo ${ }^{7}$. Assim, qualquer fisicalista coerente precisa ser reducionista ou eliminativista. De outro lado, Baker assevera uma "superveniência ampla" ou "dependência constitucional" a ponto de salvaguardar a irredutibilidade do nível superior: "a base de superveniência será muito ampla - ampla demais para ser especificada ou útil para explicação - mas será metafisicamente suficiente para a instância de propriedade constituída". A pergunta crítica é se realmente tal "superveniência ampla" da relação constitucional é suficiente para colocar Baker no rol dos fisicalistas. Baker pensa que sim e se explica da seguinte forma:

A PC-View separa constituição de superveniência: constituição é contingente e altamente dependente do contexto; superveniência é necessária e independente de contexto. No entanto, a superveniência fornece a dependência das instâncias de propriedade constituídas de seus constituintes; constituição fornece as propriedades causais referidas na explicação causal ${ }^{8}$.

Como é possível que haja simultaneamente superveniência e constituição como são definidas por Baker? Se há uma relação de superveniência, "necessária e independente de contexto", de propriedades superiores sobre suas estruturas microfísicas, como é possível ainda defender, ao mesmo tempo, uma "contingência e dependência de contexto" das propriedades constitucionais? Em que consistiria tal "contingência e dependência de contexto", uma vez que já foi afirmada uma superveniência "necessária e independente de contexto" sobre estruturas microfísicas? Em que sentido uma propriedade superior qua propriedade superior (i.e., sem que seja reduzida) pode ser superveniente (fortemente) sobre suas estruturas microfísicas? Tomemos o exemplo da estátua de bronze. Para ser uma postura fisicalista (coerente), a propriedade "ser um artefato estético" com o poder causal de "seduzir um comprador" deveria ser ("necessária e independente de contexto") superveniente ao bronze. Porém, se este for o caso, então não há mais espaço para se defender uma "contingência e dependência de contexto" dessas propriedades, como afirma Baker de suas propriedades constitucionais. Em suma: a partir de sua afirmação acima, Baker tem três

\footnotetext{
7 Até mesmo a proposta de fisicalismo mínimo de Kim se torna incoerente (cf. KIM, J., Physicalism, or something near enough, Princeton University Press: Princeton/Oxford, 2005, p. 162), pois o "resíduo mental" (os qualia), que ele admite como não reduzível ao físico e, por isso, sem nenhum poder causal, acaba gerando a seguinte questão: o que são os qualia ontologicamente? Kim responde afirmando que são "epifenômenos". Mas "epifenômenos" são algo, ou seja, um não-nada-absoluto. Ora, se este algo não é físico, como ele admite, então o fisicalismo não rege como dimensão oniabrangente.

8 "The PC View separates constitution from supervenience: Constitution is contingent and highly context-dependent; supervenience is necessary and independent of context. However, supervenience supplies the dependence of the constituted property instances on their constitutors; constitution supplies the causal properties referred to in causal explanations" (BAKER, L. R., "Nonreductive Materialism". In: MCLAUGHLIN, B./BECKERMANN, A. (eds.), The Oxford Handbook for the Philosophy of Mind. Oxford: Oxford University Press, 2009, p. 123)
} 
saídas: ou 1) defende um fisicalismo redutivo (ou eliminativo), a fim de salvaguardar sua tese da superveniência; ou 2) defende um dualismo, a fim de salvaguardar sua tese da irredutibilidade; ou, o que é pior e constitui o caso de Baker, 3) afirma as duas teses, caindo em incoerência.

De fato, esta é a incoerência de todos os fisicalismos não-reducionistas, que procuram afirmar a irredutibilidade e eficácia causal de (macro)propriedades mentais, ao mesmo tempo em que defendem uma superveniência (forte) sobre (micro)propriedades físicas. Ao final, um dos elementos permanece obscuro ao se pretender defender o outro, ou seja, caso se defenda a irredutibilidade, o conceito de "fisicalismo" não fica claro ou fraco demais para ser um monismo; caso se defenda um real "fisicalismo", o conceito de "irredutibilidade" perde o sentido. Vai nessa direção a crítica de Puntel à tese de Searle:

Searle afirma duas teses que se contradizem: (1) físico ${ }_{0} \neq$ físico $_{1}$ (p. ex.: o subâmbito mental) $\neq$ físico $_{2}$ (p. ex.: o subâmbito social) $\neq \ldots \ldots$ físico $_{n} ;$ (2) físico $_{0}=$ físico $_{1}($ p. ex.: o subâmbito mental $)=$ físico $_{2}$ (p. ex.: o subâmbito social $)=\ldots=$ físico $_{n}$. Searle conseguiria escapar da autocontradição somente se aclarasse e formulasse com precisão o conceito do físico (physical). Se for introduzida e assumida uma diferença entre o "físico" e o "não-físico", então só pode tratar-se de dois diferentes subâmbitos de um "âmbito abrangente ou fundamental" a ser pressuposto. Se, para esse âmbito abrangente ou fundamental, for empregada ou se quiser empregar mais uma vez a palavra "físico", então é preciso especificá-la com toda clareza, para distingui-la dos subâmbitos que se diferenciam em "físico" e "não-físico" .

A segunda incoerência decorre da ontologia da substância assumida. Indicamos aqui rapidamente em que consiste. A VCP assume uma ontologia da substância e atributos (propriedades e relações). No nível elementar, haveria apenas um tipo de substância, a material. No nível das propriedades, haveria uma diversidade ontológica. A pessoa seria um conjunto de propriedades superiores constituídas por propriedades físicas inferiores. Tomemos mais uma vez o exemplo da estátua de bronze, chamemo-la de $x$. O que seria $x$ para além de suas propriedades (superiores ou inferiores)? De fato, a VCP explica que a propriedade de "ser um artefato estético" é constituída pela propriedade "ser de bronze". Ora, mas nesse caso teríamos uma propriedade como portadora (bearer) de outra propriedade. Qual seria a substância das duas? Por mais que se tente, será impossível tornar o $x$, a suposta substância ou objeto, algo inteligível para além de qualquer propriedade. Tal elemento substancial, portador de propriedades, não é compreensível e vem simplesmente pressuposto na VCP. Retornaremos a este ponto mais à frente.

${ }^{9}$ PUNTEL, L.B., Estrutura e ser. Um quadro referencial teórico para uma filosofia sistemática. Trad. Nélio Schneider, São Leopoldo, Ed. Unisinos, 2008, p. 380. 
[2] Outro problema da VCP é a ausência de uma reflexão profunda sobre a linguagem e sua relação com a ontologia. Baker afirma que estados mentais, pessoalidade, intencionalidade, macropropriedades têm um status ontológico irredutível a estados físicos, mas não tematiza qual a relação entre estas entidades e a linguagem que ela mesma utiliza para explicitá-las. O grande tema da linguagem/semântica fica simplesmente pressuposto na VCP e a linguagem ordinária vem utilizada para elaborar as sentenças desta concepção. No entanto, nenhuma teoria ontológica pode ser elaborada adequadamente se não tematiza a linguagem e a questão da relação de suas sentenças com o mundo real. Caso contrário, elementos como consciência, estados mentais, intencionalidade etc. correm sério risco de passar por fatores apenas representacionais, ligados à pura subjetividade, sem nenhum valor expressivo da realidade. Lembremos que sentenças do tipo "estou com dor", "estou pensando" são sim incorrigíveis, mas não as sentenças teóricas que procuram explicar o que seja a dor, pensamentos, estados mentais. "Teorias" precisam ser elaboradas dentro de um quadro linguístico coerente e adequado, algo que as atuais teorias sobre a pessoa negligenciam. De fato, Baker não chama sua concepção de "teoria", mas de "visão" (view), talvez indicando que tenha consciência do pouco rigor teorético de suas afirmações, que podem facilmente ser interpretadas a partir de uma perspectiva subjetiva e particularista da realidade. Abaixo, vamos mostrar o porquê e como a FES se dedica a esta tarefa.

[3] Por fim, o problema mais crucial da VCP é a falta de uma metafísica do Ser, para além de uma ontologia do ente pessoa. Esta dificuldade perpassa praticamente todas as teorias atuais acerca da pessoa. Para entender esta questão, faz-se mister relembrar a famosa divisão de metafísica de Francisco Suárez no século XVI, depois assumida por Christian Wolf. Para Suárez, a metafísica era dividia em metaphysica generalis e metaphysica specialis. Enquanto a primeira tratava do ente enquanto ente (ontologia), a segunda tematizava três entes especiais: Deus (Teologia natural), mundo (Cosmologia) e alma (Psicologia racional). A metafísica da pessoa, como a conhecemos hoje, retoma a metafísica especial sobre a alma, tematizando sua natureza, seu lugar no mundo físico, o problema da liberdade etc. Foi a crítica de Heidegger à metafísica clássica que despertou a filosofia contemporânea para uma teoria geral do Ser. A tradição metafísica, segundo Heidegger, teria esquecido a diferença entre Ser e ente (ontologische Differenz), não conseguindo elaborar uma teoria do Ser, visto como uma dimensão oniabrangente e condição de possibilidade de todos os entes.

Desde Descartes, a divisão da pessoa em res cogitans e res extensa aprofundou ainda mais o esquecimento do Ser, uma vez que não se tratava de nenhuma dimensão oniabrangente, capaz de intermediar a interação entre elas. De fato, filósofos contemporâneos, herdeiros deste impasse, são incapazes de resolver o chamado "problema da interação psicofísica", devido à falta de reflexão sobre a própria diferença. $\mathrm{A}$ VCP não é uma exceção. 
A incapacidade de conciliar a irredutibilidade de estados mentais com o fisicalismo se dá porque vem assumida uma visão oniabrangente do Ser (como entidade física), que estrangula, $a b$ ovo, qualquer diferença ontológica e acaba conduzindo a VCP à total incoerência ${ }^{10}$. O grande desafio da metafísica contemporânea da pessoa é, portanto, tematizar o ser humano dentro de uma teoria mais abrangente capaz de dar conta das diferenças ontológicas existentes no ente pessoa, ao mesmo tempo em que preserva a unidade e interação entre tais dimensões.

\section{A FES e seu quadro teórico estrutural-sistemático}

A Filosofia Estrutural-Sistemática (FES) constitui uma concepção de filosofia caracterizada por dois elementos fundamentais: de um lado, pela elaboração de um quadro teórico-linguístico adequado ao empreendimento filosófico; de outro, pela construção de teorias capazes de expressar os diversos âmbitos ontológicos do mundo, culminando numa teoria do Ser como tal e em seu todo, chamada de Einailogia. No mapa geral da FES, a metafísica da pessoa se localiza na Sistemática do mundo, na qual várias subteorias sobre o mundo são elaboradas, entre elas, uma (sub)teoria da pessoa. Traço fundamental dessa (sub)teoria é não apenas a intrínseca relação entre linguagem e ontologia, mas sua inclusão numa teoria mais abrangente, a saber: numa metafísica do Ser. Neste tópico e no próximo, apresentamos resumidamente o quadro teórico básico da FES e sua (sub) teoria do ser humano, no intuito de revisitar, no tópico 5, algumas dificuldades clássicas da metafísica especial da pessoa.

A primeira tarefa para articular de forma adequada o problema da pessoa é construir um quadro teórico-linguístico coerente. Esta empreitada é quase totalmente negligenciada no presente contexto. A falha metodológica mais grave das atuais concepções consiste em assumir quadros teóricos não explicitados ou ontologias incoerentes para sustentar suas posições. Isto acontece por um descuido simples, mas fatal, a saber: elas pouco se interessam em precisar a linguagem que utilizam e acabam assumindo a linguagem ordinária de forma acrítica. Teorias elaboradas a partir dessas linguagens trazem consigo toda a ambiguidade dos termos e incoerências de sua semântica e ontologia.

${ }^{10}$ É preciso fazer aqui uma rápida alusão crítica à tese do "Fisicalismo", que é tão obscura quanto é o conceito de físico adotado. De fato, dever-se-ia recuperar o famoso "dilema de Hempel" (1970) que dava ao Fisicalismo duas opções: ou 1) entende-se por 'físico' aquilo que as teorias físicas atuais compreendem, ou 2) entende-se por 'físico' algo totalmente novo, capaz de incluir fenômenos como a consciência, o que geraria uma "nova ciência". A primeira opção não é satisfatória porque a física atual não consegue explicar fatos como a consciência ou a intencionalidade. A segunda opção é vazia porque não temos a mínima ideia do que seja uma "nova ciência física". 
Explicitemos, en passant, qual a dificuldade básica da linguagem ordinária para se elaborar teorias filosófico-científicas.

Teorias têm sempre a pretensão de mostrar ou descrever uma determinada realidade e, para isso, precisam utilizar a linguagem como meio de "exposição" e não apenas como meio de "comunicação" entre sujeitos. A função de exposição, que a linguagem possui, traz consigo a exigência de eliminar todos os elementos particularistas, vagos, ambíguos e indeterminados da linguagem. Por esta razão, antes de elaborar qualquer teoria, é indispensável corrigir pelo menos três elementos da linguagem natural, a saber: sua sintática, semântica e ontologia. Na linguagem natural, sintática e semântica assumem o princípio de composicionalidade, a partir do qual uma sentença consiste na junção de um sujeito e um predicado. Esta estrutura sintática apresenta também uma semântica composicional, na qual o sentido ou a estrutura da sentença vem determinado pela combinação do valor semântico dos dois componentes da sentença, isto é, sujeito e predicado. $\mathrm{O}$ valor semântico do sujeito é seu referente, a saber: o objeto, que na linguagem filosófica tradicional é chamado de substância; o valor semântico do predicado é o atributo, no caso mais simples, a propriedade. Como fica claro, a sintática e a semântica da linguagem natural se apoiam, por fim, numa ontologia da substância (ou do objeto), com suas propriedades e relações. A incoerência básica dessa ontologia e, por consequência da sintática e semântica composicionais, está no fato de que nunca se pode determinar o que seja uma substância para além de qualquer propriedade ou relação, como já vimos acima. Ela é praticamente ininteligível ou indeterminada per se, apenas sendo pressuposta como portadora de propriedades. A FES rejeita tal ontologia e, com ela, sua sintática e semântica, no intuito de elaborar um quadro teórico a partir de uma ontologia mais coerente, acompanhada de uma sintática e semântica contextual.

Uma rápida análise de uma sentença da linguagem ordinária pode nos ajudar a entender o procedimento da FES. Tomemos a sentença "a maçã é vermelha". Temos aqui um sujeito 'a maçã' ao qual é aplicado uma propriedade 'é vermelha'. A pergunta crítica a fazer é: o que é esta 'maçã', que a ontologia clássica chama de substância e a filosofia analítica contemporânea de objeto? Como podemos determiná-la ou torná-la inteligível? Pelo próprio conceito, substância quer dizer aquilo que está debaixo, sustentando uma propriedade. Ela não é predicável, mas é sujeito de predicação. Em nosso caso, se quiséssemos determinar em que consiste a substância 'maçã', deveríamos fazê-lo sem utilizar nenhuma propriedade, mas isto não é o que acontece. Geralmente, uma resposta que se dá à pergunta: 'o que é uma maçã?' é esta: maçã é uma fruta da espécie malus domestica. Nessa resposta, trocamos o substantivo 'maçã' pelo substantivo 'fruta' (de certa espécie). Se fizermos o mesmo procedimento com o substantivo 'fruta', chegaremos a elencar uma série de predicados tais como 'é comestível', 
'é carnoso', 'é doce' ou 'é ácido' etc. O que se fez aqui? Simplesmente não se conseguiu determinar o que seja uma 'fruta' ou 'maçã' sem a utilização de propriedades. Ora, mas "substância" é exatamente aquilo que sustenta as propriedades. Nem mesmo o fato de afirmar que há algumas propriedades essenciais e propriedades não essenciais poderia resolver $\mathrm{o}$ caso, pois a pergunta que permanece é sempre a mesma: ora, mas como se pode falar de propriedades essenciais aqui, uma vez que qualquer propriedade essencial pressuporia também uma substância? A inconsistência persiste sempre.

O procedimento da FES é diferente. No caso da sentença 'a maçã é vermelha', o que se deve fazer é rejeitar a ideia de um suporte para propriedades e entender tais propriedades como os únicos elementos inteligíveis daquele indivíduo concreto. Nesse sentido, o indivíduo seria um conjunto (a FES usa o termo "configuração") de propriedades (a FES usa o termo "fatos primos") unificadas em um determinado espaço-tempo-contexto do mundo. Assim, a nossa maçã consistiria numa configuração de fatos primos acontecendo num determinado espaço-tempo-contexto. É fácil perceber que a FES se assemelha à chamada teoria dos feixes. No entanto, a semelhança é superficial, pois também as atuais teorias dos feixes acabam adotando uma sintática e semântica composicionais (que trazem consigo a ontologia da substância). A ontologia da FES vem acompanhada de uma nova sintática e semântica, capazes de apresentá-la sem incoerência. De fato, uma das teses fundamentais da FES é a conexão intrínseca entre ontologia e semântica, de tal forma que não se pode revisar uma ontologia sem que se revise também sua semântica e vice-versa. Como elaborar uma sintática e semântica condizentes com esta ontologia configuracional?

Um passo fundamental representa a elaboração de uma estrutura sintática sem a estrutura sujeito-predicado, na medida em que tal estrutura pressupõe a ontologia rejeitada. A FES adota a forma de sentenças teóricas de Wittgenstein: "é o caso que" (es verhält sich so und so"), que funciona como um operador à frente de um argumento, chamando tais sentenças de sentenças primas. Dessa forma, podemos transformar as antigas "propriedades" em "sentenças primas" e entender um indivíduo qualquer como uma configuração de sentenças primas. Voltando à nossa maçã, podemos afirmar as seguintes sentenças primas: "é o caso que vermelho", "é o caso que doce", "é o caso que carnosa" etc. Ora, mas sentenças constituem um conjunto de elementos linguísticos que expressam uma informação, que usualmente se nomeia de proposição. Na FES, sentenças primas expressam proposições primas, entendidas como um todo informacional sem a estrutura sujeito-predicado. Isso significa que nosso indivíduo "maçã" constitui uma configuração de sentenças primas, que expressam proposições primas. Por fim, quando proposições primas são verdadeiras, podemos chamá-las de fatos primos. Ou seja, proposições primas verdadeiras são idênticas a fatos primos ocorrendo no mundo. Assim, vê-se a ligação intrínseca entre 
linguagem (com sua sintática e semântica) e ontologia, quando se atesta que proposições primas são capazes de expressar ou articular o mundo, também esse expressável ou articulável pela linguagem.

Dessa forma, os chamados "particulares" são entendidos como uma configuração de fatos primos, que podem ser classificados de acordo com: 1) número de fatos primos; 2) tipos de fatos primos; 3) ordenação dos fatos primos e 4) fator unificador ${ }^{11}$. O primeiro constitui um fator material e significa a quantidade de fatos primos expressos numa configuração. $\mathrm{O}$ segundo constitui um fator formal, que distingue os fatos primos de acordo com sua espécie (fatos primos estáticos, dinâmicos, processuais, eventivos, concretos, abstratos, ideais etc.), sua complexidade (fatos primos simples ou complexos) e sua diferencialidade ontológica (fatos primos materiais, físicos, biológicos, espirituais ("mentais"), lógicos, matemáticos, ideais, axiológicos, morais, éticos, jurídicos, institucionais, sociais, estéticos etc.). $\mathrm{O}$ terceiro ponto representa o modo como a configuração se apresenta, ou seja: a forma como os fatos primos estão sequenciados e interconectados, o que determinará (junto aos outros dois fatores) a distinção de um indivíduo de outro. Enfim, o quarto ponto se refere ao fator unificador da configuração. Na realidade, cada configuração tem seu elemento unificador próprio, mas, de modo geral, pode-se afirmar que configurações apresentam como condição necessária, embora não suficiente, a copresença dos fatos primos envolvidos. O que nos interessa aqui é analisar a configuração pessoa humana e esclarecer quais são os fatos primos envolvidos, qual a espécie, a complexidade, a constituição ontológica desses fatos primos, como eles se apresentam ordenados e qual o fator de unificação desta configuração robusta.

\section{Pessoa humana como configuração de fatos primos}

Como vimos na crítica à VCP, o grande desafio de uma atual teoria da pessoa representa a elaboração de uma concepção capaz de salvaguardar a originalidade ontológica das várias dimensões da pessoa, ao mesmo tempo em que conecta esta diversidade ontológica num todo coerente. Nem dualistas, nem fisicalistas reducionistas e, muito menos, fisicalistas não-reducionistas foram capazes de executar esta tarefa de forma adequada. Cabe aqui apresentar a Teoria Holístico-Configuracional de pessoa (THC) a partir do quadro teórico da FES.

Segundo a THC, o indivíduo "pessoa" é entendido como uma configuração de fatos primos. Pode-se dividir a heterogeneidade dos fatos primos da

\footnotetext{
${ }^{11}$ Cf. PUNTEL, L.B., Estrutura e ser. Um quadro referencial teórico para uma filosofia sistemática. Trad. Nélio Schneider, São Leopoldo, Ed. Unisinos, 2008, p. 350.
} 
configuração pessoa humana de duas formas: uma modal e outra específica da área ${ }^{12}$. A forma modal apresenta três divisões: 1) fatos primos que têm uma forma absolutamente essencial ou necessária para a configuração pessoa, independentemente da cor, religião, história, situação geográfica. Eles são fatores ontológicos inerentes, quais sejam: a inteligência, a vontade (livre), a consciência ou autoconsciência. Estes elementos constituem aquilo que a tradição filosófica chama de espirito ${ }^{13}$; 2) fatos primos com uma forma relativamente ou historicamente essencial, que não podem faltar na configuração pessoa enquanto está situada no espaço-tempo, como por exemplo: "ter um corpo", "ter nascido", "crescer", "morrer" ou, ainda, aqueles fatores adquiridos na história e que estão indexados a alguém durante toda a sua existência: "ter-se graduado", "ter-se tornado mãe", "ter irmãos" etc; 3) fatos primos com uma forma contingente, que surgem e/ou (podem) desaparecem historicamente: "usar uma gravata", "pegar um ônibus" etc.

Além dessa complexidade modal, é preciso diferenciar os diversos âmbitos ontológicos específicos da configuração pessoa, como sejam: fatos primos puramente espirituais (mentais), sociais, sensíveis, biológicos, puramente físicos, além de outras diferenciações dentro de cada âmbito específico. É nesse ponto que surge o problema da (inter)conexão entre estes níveis ontológicos: como dar conta da interação entre as diferentes dimensões da pessoa sem cair num dualismo cartesiano ou monismo reducionista?

Antes de enfrentar esta dificuldade, cabe uma reflexão metodológica importante. Um quadro teórico-linguístico não unifica a realidade como se fosse uma imposição da linguagem sobre o mundo, a fim de proporcionar significado ao teórico. $\mathrm{O}$ que faz um adequado quadro teórico-linguístico é explicitar, articular a estruturalidade intrínseca do mundo de tal forma que a unidade estrutural da realidade seja expressa. Em nosso caso, isto significa que os diversos tipos de fatos primos envolvidos na configuração "pessoa" não constituem um feixe de coisas separadas, unificado posteriormente por qualquer fator, mas constituem a priori um todo ontológico, explicitado a posteriori por um quadro teórico linguístico. Este estado de coisas indica que a distinção entre linguagem e ontologia, ou melhor, entre a dimensão estrutural e a dimensão dos dados é uma distinção apenas abstrata, pois, de fato, as duas dimensões constituem dois lados de uma mesma realidade.

${ }^{12}$ Cf. PUNTEL, L.B., Estrutura e ser. Um quadro referencial teórico para uma filosofia sistemática. Trad. Nélio Schneider, São Leopoldo, Ed. Unisinos, 2008, p. 363.

${ }^{13}$ Lembremos que estes elementos não são "propriedades" aplicadas a uma "substância", mas são fatos primos articulados por sentenças primas: "é o caso que tendo intelecto", "é o caso que tendo vontade", "é o caso que tendo consciência" etc. e unificados numa configuração. 
Fato incorrigível é que a pessoa humana experimenta a si própria como um todo unificado, que persiste ao longo do tempo ${ }^{14}$. Todas as teorias procuram determinar o fator explicativo deste fenômeno, ao levantar a seguinte questão: o que faz com que pessoa em tempo $_{1}$ seja idêntica à pessoa ${ }_{2}$ em tempo $\mathrm{P}_{2}$ ? Algumas teorias, como os vários tipos de animalismos, assumem o corpo como o fator unificante, outras, como as teorias neolockeanas, assumem os estados psicológicos; outra ainda, como a VCP, apela para uma relação constitucional entre corpo e perspectiva em primeira pessoa. A FES vê problema em todas estas concepções, seja porque representam teorias reducionistas, seja porque não conseguem garantir a unidade fundamental da pessoa em suas várias dimensões, seja porque são simplesmente incoerentes. Para a THC, o fator unificante da pessoa constitui um ponto de unidade sistemático-ontológico irredutível, que se articula no dizer-"eu". Este ponto de unidade não se reduz a um fator psicológico, fenomenológico ou linguístico, mas possui um status ontológico original que se caracteriza como o "ponto de interseção" dos fatos primos da pessoa. Quer dizer, todos os fatos primos envolvidos se encontram e são perpassados pelo ponto de unidade, que constitui a expressão da unidade primordial ${ }^{15}$.

A característica crucial do dizer-"eu" deriva do fato primo absolutamente essencial da inteligência (mas também da vontade e (auto)consciência) ${ }^{16} \mathrm{e}$ é a seguinte: sua coextensividade intencional com o universo. Isto significa que a configuração pessoa pode se referir intencionalmente a qualquer coisa do mundo, não encontrando limites para o seu raio intencional. Este fato mostra que a configuração pessoa se relaciona com tudo (com o Ser como tal e em seu todo), situando-se dentro deste universo como um ponto sistemático. Se pudéssemos retratar este fato com uma figura geométrica, poderíamos imaginar um círculo com um ponto no meio, de onde saem linhas que

\footnotetext{
${ }^{14}$ De fato, experimentamos a nós mesmos como um todo unificado. Se tal experiência é corrigível ou não, vai depender do tipo de experiência que fazemos. Pode-se distinguir entre experiências imediatas e mediatas de nosso "eu". Experiências imediatas são aqueles estados mentais articulados pela linguagem natural, dos quais não posso errar em minha percepção, ou seja, são incorrigíveis, como por exemplo: "eu estou pensando", "eu estou sentindo uma dor" etc. Experiências mediatas são aquelas articuladas dentro de um quadro teórico "irrefletido", quando, por exemplo, aprendemos que temos "uma alma dentro de nós" (cf. PUNTEL, L.B., Estrutura e ser. Um quadro referencial teórico para uma filosofia sistemática. Trad. Nélio Schneider, São Leopoldo, Ed. Unisinos, 2008, p. 362). Assim, enquanto as experiências mediatas podem ser melhor explicitadas ou até mesmo refutadas, nenhuma teoria filosófica ou científica pode refutar uma experiência imediata (como aquela de que me experimento como um todo ou que experimento uma dor). Eis a razão pela qual o fisicalismo eliminativo se engana ao pensar que "estados mentais" são uma mera criação de uma psicologia popular (folk psychology) (cf. VIANA, W.C., Hans Jonas e a filosofia da mente, São Paulo: Paulus, 2016, p. 50). ${ }_{15}$ Afirmar que o dizer-"eu" consiste na expressão da unidade é fundamental para esta concepção, pois o dizer-"eu" não é um fator a posteriori que cria a unidade psicofísica do indivíduo. Ele apenas expressa tal unidade ontológica por meio da linguagem.

${ }^{16}$ É certo que a intencionalidade da inteligência, vontade e consciência apresentam modos diferentes (cf. PUNTEL, L.B., Estrutura e ser. Um quadro referencial teórico para uma filosofia sistemática. Trad. Nélio Schneider, São Leopoldo, Ed. Unisinos, 2008, p. 369ss).
} 
tocam cada ponto do círculo. À diferença da figura, na configuração pessoa, até mesmo o ponto sistemático vem atingido por seu raio intencional, ou seja, o "eu" lança também um raio sobre si próprio (autoconsciência). É a partir desta característica que se pode defender a irredutibilidade do "eu" em relação a outras dimensões, como a físico-neurológica, e garantir seu "local intencional-sistemático" no Ser como um todo.

Com o esclarecimento do fator configurador da pessoa, Puntel estabelece seu critério de identidade pessoal, ou seja: aquele critério que determina se uma pessoa ${ }_{1}$ num tempo ${ }_{1}$ é idêntica a uma pessoa ${ }_{2}$ num tempo ${ }_{2}$ Para a FES, tal critério constitui saber se as duas configurações têm o mesmo local intencional-sistemático, havendo duas condições para se estabelecer este fato ${ }^{17}$ :

a) Condição material: as duas configurações precisam ter os mesmos fatos primos;

b) Condição formal: todos os fatos primos devem estar numa mesma sequência e com as mesmas interconexões.

Apresentada a THC, cabe agora perguntar como tal teoria enfrenta os impasses clássicos e contemporâneos da metafísica da pessoa, sobretudo, aqueles da irredutibilidade de estados mentais e interação psicofísica. Haveria uma infinidade de outras questões a serem abordadas e reinterpretadas a partir da THC, mas isso não é possível nos limites deste artigo.

\section{Metafísica da pessoa revisitada}

Apesar da FES rejeitar o fisicalismo não reducionista, ela defende teses parecidas, pelo menos à primeira vista, a saber: 1c) há uma diversidade ontológica de fatos primos; 2 c) há uma conexão entre fatos primos mentais e físicos e 3c) fatos primos mentais são causalmente eficazes no mundo físico. A questão agora é saber como se pode defender tais teses sem cair nos braços dos dois rivais: do fisicalismo (eliminativo ou reducionista) ou do dualismo. Para iniciar, pode-se concluir das teses acima que a FES rejeita o fisicalismo em todas as suas formas. Não temos como apresentar aqui o argumento da FES contra o fisicalismo ${ }^{18}$. Ao invés disso, vamos nos concentrar em combater o segundo rival, o dualismo, sem deixar de ressaltar o que nele há de significativo, a saber: a irredutibilidade do mental em relação ao físico, nem muito menos deixar de responder à sua dificuldade com a interação psicofísica.

${ }_{17}$ PUNTEL, L.B., Estrutura e ser. Um quadro referencial teórico para uma filosofia sistemática. Trad. Nélio Schneider, São Leopoldo, Ed. Unisinos, 2008, p. 369.

${ }^{18}$ Cf. este argumento em PUNTEL, L.B., Estrutura e ser. Um quadro referencial teórico para uma filosofia sistemática. Trad. Nélio Schneider, São Leopoldo, Ed. Unisinos, 2008, p. 380ss 
A THC afirmou uma diversidade ontológica de fatos primos na configuração pessoa. A questão básica que surge é esta: como tais fatos primos podem interagir, dada tal diversidade ontológica? A FES rejeita o dualismo cartesiano, não apenas porque constitui uma ontologia da substância, mas também porque defende uma radical separação entre mental e físico, de tal forma que se torna impossível qualquer tipo de interação entre eles. O erro de Descartes foi, simplesmente, não ter refletido sobre a diferença, o que lhe impediu de encontrar uma metadimensão comum à res cogitans e res extensa. De fato, nenhuma diferença pode ser vista ou compreendida sem que haja uma dimensão comum que as interconecte. Para o fisicalismo, tal dimensão oniabrangente é a dimensão física. Para a FES, ela constitui a dimensão do Ser como tal e em seu todo. Nessa visão, o mental e o físico não são duas dimensões isoladas e separadas, mas dois modos do Ser se apresentar. Dito de outra forma: aquilo que mental e físico possuem em comum é pertencerem ambos à dimensão oniabrangente do Ser, que constitui a conexão interna que permeia qualquer diversidade ontológica e constitui o fator capaz de diluir o secular problema da interação entre mental e físico. Explicitemos melhor este estado de coisas a partir de três questões interligadas: 1) como o mental surgiu na evolução; 2) como é possível uma causalidade entre mental e físico e 3) como não ocorre uma microdeterminação de estados mentais por estados neuronais.

[1] Uma questão a ser resolvida neste modelo é entender como o mental surgiu na evolução, caso se aceite sua irredutibilidade. Damos aqui apenas uma ideia geral do que poderia ser uma solução. A THC parte de um princípio tão trivial quanto fundamental, que a FES chama de Princípio do fechamento holístico (PFH). Ele afirma o seguinte: "Tudo o que acontece no processo evolutivo do universo foi, desde o início, uma potencialidade ontológica, entendida como um fator estrutural imanente do processo como um todo"19. A partir deste princípio, a FES aceita dois elementos importantes nessa discussão: 1) o mental apareceu no curso da evolução e 2) o mental não foi causado por processos físicos, mas foi manifestado no processo evolutivo. A ideia de manifestação, atualização ou desdobramento (unfolding) ajuda a entender o que se compreende com o PFH. Toda a diversidade ontológica já estava presente como potencialidade no processo evolutivo do universo (isto é, da dimensão contingente do Ser como um todo), apenas se manifestando em determinado momento da evolução. Assim, o mental não surgiu como uma "novidade radical", como afirmam os emergentistas no intuito de defender a irredutibilidade do mental, mas já estava presente como potência no todo da evolução ${ }^{20}$. Nem se confunda

\footnotetext{
${ }^{19}$ Cf. PUNTEL, L.B., "Response to Prof. Sovik's Letter", artigo não publicado, 2015.

${ }^{20}$ Nesse sentido, Hans Jonas apresenta uma intuição esclarecedora ao afirmar que, no início da evolução, não havia certamente um logos informativo, determinando cada degrau do processo, mas apenas um eros cosmogônico, capaz de indicar o horizonte da evolução (cf. JONAS, H., Matéria, espírito e criação. Petrópolis, RJ: Ed. Vozes, 2010, p. 13).
} 
a posição da FES com a do pampsiquismo. A diferença básica é que a FES não assume entidades "protoconscientes" na evolução, como se o mundo físico, em última análise, fosse reduzido ao psíquico. Ao contrário, mental e físico são dimensões irredutíveis uma à outra, mas permeadas pela dimensão oniabrangente do Ser como um todo. Haveria muito a esclarecer neste modelo, mas temos que nos limitar aqui apenas a esta questão geral.

[2] Outra questão é entender como se dá a conexão causal entre mental e físico. Como vimos acima, a VCP defende uma relação dupla: de um lado, há uma relação de superveniência, que deveria sustentar seu fisicalismo; de outro, uma relação de constituição, que deveria sustentar a irredutibilidade das propriedades mais elevadas. No quadro teórica da FES, fundamental será o conceito de configuração, que também admite uma (fraca) superveniência/subveniência entre mental e físico. De fato, há um problema com a ideia de "constituição" ou "realização" de propriedades mentais através/em propriedades físicas, a saber: o status ontológico das "propriedades superiores" não fica claro, pois a relação de constituição acaba se confundindo com a de superveniência (forte) e escurece a singularidade ontológica das propriedades superiores, mesmo que lhes sejam reconhecidos poderes causais próprios. Com o termo configuração a FES pensa diferente, pois o todo configuracional vem assumido com os poderes causais próprios de cada âmbito ontológico (físico, biológico, mental, ético, estético etc.), sempre numa interconexão entre eles e reunidos, como vimos acima, no ponto sistemático do "dizer-eu", que perpassa intencionalmente todos os fatos primos envolvidos.

Talvez a grande dificuldade para entender a interação da diversidade ontológica, sobretudo, entre fatos primos mentais e físicos-neuronais advenha de alguns axiomas metodológicos do fisicalismo. Um deles constitui o chamado princípio do fechamento causal do mundo físico (PFC), que afirma: "todo efeito físico, tem também uma causa física". Se tal princípio fosse válido, ficaria difícil de entender como fatos primos mentais poderiam influenciar fatos primos físicos ou vice-versa. O PFC pode apresentar três versões: uma fraca, uma forte e outra fortíssima ${ }^{21}$. A versão fraca não excluiria a interferência de causas não físicas, mostrando que um efeito físico pode ser sobredeterminado por uma causa não física. A versão forte é completada com o princípio da exclusão causal (PEC), que afirma: "todo efeito físico tem apenas uma causa física". Por fim, a versão fortíssima excluiria não somente uma influência do mental no físico, mas também do físico no mental.

Rejeitar o PFC parece trazer embaraços para a física, sobretudo: como explicar a lei de conservação da energia, caso se admita a influência do

${ }^{21}$ Cf. VIANA, W.C., Hans Jonas e a filosofia da mente, São Paulo: Paulus, 2016, p. 160. 
mental sobre o físico? Poderia o mental injetar energia no mundo físico? No entanto, tal problema surge porque se assume um conceito bem determinado de causalidade, a saber: aquele de troca de energia, momentum entre eventos. Esta compreensão, porém, é muito limitada. Há formas mais largas de se entender causalidade que podem ser coadunadas com a abertura causal do mundo físico e que têm forte poder explicativo ${ }^{22}$. $\mathrm{Na}$ realidade, o PFC constitui apenas um pressuposto metodológico do fisicalismo e não uma regra da natureza. Aceitá-lo de modo absoluto seria desastroso para nossa compreensão de pessoa e mundo, uma vez que cairia por terra qualquer ideia de liberdade, responsabilidade, moralidade etc. Se quiséssemos, nessa hipótese, salvar qualquer interação com o mundo físico, deveríamos reduzir a subjetividade ao mundo físico, o que, por si, já traz suas próprias contradições, como veremos abaixo. Mais uma vez, segundo a FES, o imaterialismo de Descartes não constitui seu erro, senão o radical isolamento das duas entidades. Quando este obstáculo é superado, não existe razão suficiente para negar o imaterialismo de estados mentais. Além do mais, pode-se questionar a generalização do PFC a partir da própria incompletude da física e da passagem da física clássica-determinística para a mecânica quântica ${ }^{23}$.

Ora, a FES rejeita as versões forte e fortíssima do PFC e os substitui pelo princípio do fechamento holístico (PFH). A partir de $\mathrm{PFH}$, não há dificuldades para explicar porque fatos primos mentais podem influenciar fatos primos físicos dentro do todo configuracional. De fato, o todo possui dimensões diferentes, mas todas interconectadas pela dimensão oniabrangente do $\mathrm{Ser}^{24}$. Isto significa que o PFC perde totalmente seu peso restritivo, no momento em que físico e mental não representam mais dois âmbitos ontológicos contrapostos.

\footnotetext{
${ }^{22}$ Cito aqui apenas um exemplo: a concepção intervencionista de J. Woorward (cf. WOORWARD, J., Making things happen, Oxford: Oxford University Press, 2003), que, embora sendo uma análise ainda insuficiente de causalidade, é mais abrangente que a visão, por exemplo, de W. Salmon (cf. SALMON, W., Scientific explanation and the causal structure of the world. Princeton, NJ: Princeton University Press, 1984).

${ }^{23}$ Há muitos modelos interacionistas que se utilizam da mecânica quântica para sustentar a ideia de que haja uma influência causal de estados mentais (irredutíveis) no mundo físico. Cf. VIANA, W.C., Hans Jonas e a filosofia da mente, São Paulo: Paulus, 2016, cap. 10.

${ }^{24} \mathrm{O}$ Ser como tal e em seu todo abrange as dimensões necessária e contingente do Ser. Para se referir apenas à dimensão contingente, Puntel usa em geral o termo "mundo", mas sempre introduzindo as seguintes distinções fundamentais, que especificam este conceito: mundo atual-concreto, mundo atual-abstrato, mundo atual-integral como a união ou junção destes dois mundos. Sobretudo em seus últimos escritos Puntel usa também o termo alemão Seiendheit (em português, pode-se traduzir pelo neologismo "Entitatividade") para significar toda a dimensão dos entes. Esta enorme dimensão tem um caráter contingente, sob uma importante ressalva: os entes "abstratos" (lógicos/matemáticos/formais) não são contingentes, quando considerados "em si mesmos" (como pensados pela mente divina), ou seja, não são contingentes em sentido absoluto, mas são contingentes em sentido relativo, isto é, com respeito à sua aplicação ou não-aplicação aos entes que são contingentes em sentido absoluto.
} 
[3] Por fim, é importante abordar a suposta microdeterminação de estados mentais por estados neuronais. A tese da microdeterminação tem se baseado nos avanços da neurociência, que mostram uma correspondência entre estados mentais e estados neuronais (easy problem), levando muitas teorias a reduzirem ou, simplesmente, eliminarem estados mentais. Contudo, a mera correspondência não justifica a opção radical pela redução ou eliminação, como se o problema duro (hard problem) de saber como ambos os âmbitos se relacionam, já estivesse resolvido. Estados mentais não podem ser reduzidos a estados neuronais porque estados mentais são coextensivos com o universo, com o Ser em seu todo (inclusive consigo mesmo), enquanto estados neuronais não possuem esta capacidade. O que poderia significar, numa versão fisicalista, que estados neuronais são coextensivos com o universo? Isso é impossível.

A correspondência entre mental e físico não constitui um problema para a concepção da FES, pois não se nega uma superveniência fraca de estados mentais sobre estados neuronais. A correspondência pode apontar, não para uma relação de constituição ou identidade, mas para uma conexão instrumental $^{25}$. Com este conceito, defende-se a seguinte tese: a pessoa humana não pensa com o cérebro ou estados neuronais, mas com a inteligência através de estados neuronais. Ou seja, o cérebro não é o órgão do intelecto da mesma forma que o ouvido é o órgão da audição, pelo fato de que o intelecto possui seu "objeto" de forma intencional, enquanto os sentidos possuem seu "objeto" de forma física. O objeto do intelecto é o inteligível, o compreensível, enquanto o objeto dos sentidos são as coisas físicas do mundo. O fato de a inteligência ser capaz de apreender fatos primos ideais como proposições verdadeiras, estruturas lógicas e matemáticas etc. mostra que não é o cérebro a realizar a operação do pensar, uma vez que é impossível reduzir tais "objetos" a estados neuronais. Realmente, é difícil conceber a ideia de que, por exemplo, os teoremas da incompletude de Gödel eram apenas representações subjetivas e que podiam ser reduzidos aos estados neuronais de Gödel, apesar de continuarem valendo ainda hoje.

Em resumo: não pode haver microdeterminação neuronal porque estados físicos não podem ser coextensivos com o Ser em seu todo da forma como podem ser estados mentais. Isto não significa que estados mentais possam dispensar estados neuronais. Como vimos, a corporalidade constitui um fato primo historicamente essencial da pessoa e ninguém consegue, enquanto está no tempo-espaço, exercitar a inteligência sem o cérebro. Assim, do ponto de vista corporal, a pessoa está submetida a todas as leis físicas

\footnotetext{
${ }^{25}$ Isto significa também que a relação de superveniência não é uma função bijectiva, ou seja, uma correspondência uma-a-uma entre mental e físico, confirmando a múltipla realizabilidade de configurações mentais. A dimensão mental (espiritual) como um todo supervem (de forma fraca) sobre sua base física, o que significa apenas que o espírito humano é, no tempo-espaço, um espírito encarnado, isto é, ele tem a corporalidade como fato primo historicamente essencial.
} 
deterministas ou indeterministas da natureza. Porém, enquanto possui uma dimensão espiritual, a pessoa interage de forma livre (macrodeterminação) e compatível com as leis do mundo físico ${ }^{26}$.

\section{Conclusão}

Uma infinidade de outras questões deveriam ser analisadas nesse modelo, o que não é possível nos limites deste artigo. O que se pretendeu foi nada mais que esclarecer as bases da discussão sobre a metafísica da pessoa em contexto analítico. Vimos que o problema fundamental foi herdado da modernidade, a saber: o dualismo radical entre res extensa e res cogitans, capaz de destruir qualquer possibilidade de interação entre elas. As tentativas de (dis)solução se resumiram em negar a originalidade ontológica de uma das partes, gerando os monismos materialista e idealista. Teorias fisicalistas não reducionistas atuais procuram fazer uma síntese entre irredutibilidade ontológica e capacidade de interação, mas incorrem em incoerência patente, como acontece com a visão constitucional de Lynne R. Baker. A tentativa da FES se diferencia das atuais propostas devido à elaboração meticulosa de um quadro teórico linguístico, capaz de expressar a diversidade ontológica da pessoa a partir de uma teoria oniabrangente. Mente e corpo pertencem a âmbitos ontológicos diversos e irredutíveis, mas interconectados pela dimensão do Ser como tal e em seu todo. Esta tese tem consequências radicais para uma metafísica da pessoa, que não podem ser subestimadas. Uma delas representa não mais que salvar o fenômeno ou intuição básica de que a pessoa humana é um todo diferenciado e que age livre e responsavelmente no mundo físico.

\section{Bibliografia}

-BAKER, L. R., “Nonreductive Materialism". In: MCLAUGHLIN, B./BECKERMANN, A. (eds.), The Oxford Handbook for the Philosophy of Mind. Oxford: Oxford University Press, 2009, 109-120.

- JONAS, H., Matéria, espírito e criação. Petrópolis, RJ: Ed. Vozes, 2010.

- KIM, J., Physicalism, or something near enough, Princeton University Press: Princeton/Oxford, 2005.

\footnotetext{
${ }^{26}$ A FES defende o compatibilismo entre natureza e liberdade, combatendo qualquer "falácia mereológica" que tome a parte pelo todo ou sugira que decisões de comportamento são tomadas por genes ou estados neuronais. Decisões livres são tomadas pela pessoa como um todo e não por partes físicas, que são incapazes de intencionalidade.
} 
- MONTGOMERY, H. A./ROUTLEY, F. R., Contingency and non-contingency bases for normal modal logics. LA Vol. 9 (no. 35-36), 1966, 318-328.

- PUNTEL, L.B., “Response to Prof. Sovik's Letter”, artigo não publicado, 2015.

- PUNTEL, L.B., Estrutura e ser. Um quadro referencial teórico para uma filosofia sistemática. Trad. Nélio Schneider, São Leopoldo, Ed. Unisinos, 2008.

- SALMON, W., Scientific explanation and the causal structure of the world. Princeton, NJ: Princeton University Press, 1984.

- VIANA, W. C., A metafísica da pessoa: o problema da identidade pessoal no debate contemporâneo, São Paulo: Ideias\&Letras, 2019.

- VIANA, W.C., A filosofia estrutural-sistemática: uma análise interpretativo-sistemática, São Leopoldo: Unisinos, 2019.

- VIANA, W.C., Hans Jonas e a filosofia da mente, São Paulo: Paulus, 2016.

- WOORWARD, J., Making things happen, Oxford: Oxford University Press, 2003.

Endereço do Autor:

Collegio Pio Brasiliano

Via Aurelia, 527

00165 Roma - Italia

wellistony_carvalho@hotmail.com 